\title{
Multilevel control of extracellular sucrose metabolism in Streptococcus salivarius by sucrose
}

\author{
P. TOWNSEND-LaWMaN ${ }^{1}$ and A. S. Bleiweis ${ }^{1,2 *}$ \\ ${ }^{1}$ Department of Immunology and Medical Microbiology, College of Medicine, University of Florida, Gainesville, \\ Florida 32610, USA \\ ${ }^{2}$ Department of Oral Biology, College of Dentistry, University of Florida, Gainesville, Florida 32610, USA
}

(Received 11 May 1990; revised 17 August 1990; accepted 6 September 1990)

\begin{abstract}
Standardized experimental conditions were established to test the role of sucrose in the regulation and control of its metabolism in Streptococcus salivarius. A fresh isolate of $\boldsymbol{S}$. salivarius was used. The extracellular dextranase activity of cells grown on sucrose was 10-fold higher than that of cells grown on glucose, fructose or galactose. This activity increased in less than $5 \mathrm{~min}$ following the addition of sucrose to galactose-grown cells, a phenomenon which was affected by neither rifampicin nor chloramphenicol which inhibit transcription and translation, respectively. Extracellular fructanase activity was 2-fold higher when cells were grown on sucrose than when they were grown on the other sugars. This increase also occurred within $5 \mathrm{~min}$, but was diminished by transcriptional and translational inhibitors. De novo synthesis was required for the production of extracellular glucosyltransferase (GTF) activity which, upon the addition of sucrose, became associated with the cell surface. Conversely, cellassociated fructosyltransferase (FTF) activity appeared to require genetic induction for its production and cellsurface association, but required sucrose for its release from the surface framework. Versatility in the control mechanisms of this complex set of enzymes allows their expression and function to be regulated at several widely separated stages in the life histories of these proteins.
\end{abstract}

\section{Introduction}

Sucrose has a marked impact on the microbial ecology of the oral cavity. This common disaccharide enhances plaque development, and is associated with dental caries (de Stoppelaar et al., 1970; Carlsson \& Johansson, 1973; Gibbons \& van Houte, 1973; Hamada \& Slade, 1980). Streptococcal enzymes which metabolize sucrose, some synthesizing polysaccharides important in microbial adhesion or cohesion (Gibbons \& van Houte, 1975; Wenham et al., 1981; Koga et al., 1986), and others hydrolysing these polysaccharide products, are virulence factors in the mutans group of oral streptococci (Curtiss et al., 1987; Sato et al., 1987; Schroeder et al., 1989). However, little has been done to study the analogous enzymes in Streptococcus salivarius, a major inhabitant of the soft tissues of the oral cavity.

The complex system of extracellular enzymes involved in sucrose metabolism include: glucosyltransferases (GTFs; EC 2.4.1.5), which catalyse the synthesis of

\footnotetext{
Abbreviations: FTF, fructosyltransferase; GTF, glucosyltransferase; CDM, chemically defined medium.
}

glucans from sucrose; fructosyltransferases (FTFs; EC 2.4.1.10), which catalyse the synthesis of fructans, either levan or inulin, from sucrose; dextranase $(1,6-\alpha-$ glucan hydrolase; EC 3.2.1.11), which partially degrades glucan; and fructanase ( $\beta$-D-fructan fructohydrolase; EC 3.2.1.80), which releases free fructose by hydrolysing fructan polymers. Since these enzymes are produced in the absence of substrate, they have been assumed to be constitutive in oral streptococci (Janda \& Kuramitsu, 1978; Wenham et al., 1979). Although there have been suggestions in the literature that this might not be the case (Keevil et al., 1983; Walker et al., 1983; Walker \& Jacques, 1987), it has been difficult to show conclusively that these enzymes are under any kind of regulatory control. This has been due to difficulties in isolating individual enzymes, variation between strains, differences in enzyme production due to growth conditions, and the general complexity in the network of these and other enzymes which metabolize sucrose.

$S$. salivarius is a common inhabitant of the oral cavity, preferentially colonizing the tongue dorsum and buccal epithelium (Weerkamp \& McBride, 1980) as well as being found in the saliva. Although it is not known to be 
a major oral pathogen, this species possesses a variety of anabolic (i.e. GTF, FTF) and catabolic (i.e. dextranase, fructanase) extracellular enzymes associated with sucrose metabolism (Chassy et al., 1976; Takahashi et al., 1983; Houck et al., 1987). Studies described below indicate that sucrose plays a role in the regulation of its metabolism in this microbial species, and that significant versatility is maintained in the mechanisms by which this is accomplished.

\section{Methods}

Bacterial strain and growth conditions. A fresh isolate of $S$. salivarius was used in these studies. This isolate, designated PC-1, was isolated in this laboratory. Subculturing was kept to a minimum by using stock cultures maintained at $-70^{\circ} \mathrm{C}$ in $25 \%(v / v)$ glycerol. A chemically defined medium (CDM), prepared according to Terleckyj et al. (1975) was used for bacterial growth in all experiments described in this paper. The energy source (sugar) varied depending on the experimental conditions as described in Results. Reagent grade sugars were purchased from Sigma. All cultures were grown at $37^{\circ} \mathrm{C}$.

Cell growth, harvest and preparation. Growth curves were generated by inoculating $\mathrm{CDM}$ or $\mathrm{CDM} /$ sugar (glucose, fructose, galactose, glucosamine or sucrose) $(10 \mathrm{mM})$ with a CDM/glucose (10 mM) starter culture at a 1:10 ratio. A Klett-Summerson photoelectric colorimeter, with a no. 54 filter, was used to take optical density measurements every 30 min until stationary phase was reached. Each data point in Fig. 1 represents the mean of triplicate samples from a representative experiment. The $\mathrm{pH}$ of each culture was determined at the same time intervals using colorpHast indicator sticks (MC/B Manufacturing Chemists).

To establish the basal level of the enzyme activities in $S$. salivarius cells, a CDM/glucose (10 mM) starter culture was added at a ratio of $1: 10$ to $\mathrm{CDM} / \mathrm{glucose}$, fructose, galactose or sucrose. When cultures reached the desired density (Klett 75 ) the cells were harvested by filtration using a $0.2 \mu \mathrm{m}$ membrane filter (Gelman Sciences), washed once with $50 \mathrm{~mm}$-potassium phosphate buffer, pH 6.35 (the buffer used throughout this study), collected by centrifugation $\left(4000 \mathrm{~g}, 20^{\circ} \mathrm{C}\right.$, $5 \mathrm{~min}$ ), and then resuspended to a 10 -fold concentration equivalent in the same buffer containing $10 \mathrm{mM}-\mathrm{NaF}$ (McCabe \& Smith, 1975). The cells were held at $4^{\circ} \mathrm{C}$ until enzyme assays were performed (within $24 \mathrm{~h}$ ). The supernatants from these cultures were concentrated immediately using Centriprep concentrators (Amicon) at $3000 \mathrm{~g}$, dialysed overnight and reconstituted to a 10-fold concentration equivalent in the potassium phosphate buffer. The supernatants were assayed for enzyme activity after dialysis.

For sucrose-shift assays, a PC-1 starter culture, grown as above, was added to CDM/galactose. This culture was grown to a Klett reading of 75. At this time, sucrose was added to a final concentration of $10 \mathrm{mM}$, and aliquots were taken over time as indicated in Figs 3 and 6 . The cells and culture fluids were then harvested and concentrated as above. Aliquots of cells collected from CDM/galactose cultures were also washed vigorously (vortexed) twice with $0.04 \%$ SDS and several concentrations of Tween $80(0.02,0.04$ and $0.06 \%)$, and twice with 50 mM-potassium phosphate buffer, pH 6.35. The cells were harvested by centrifugation $\left(4000 \mathrm{~g}, 20^{\circ} \mathrm{C}, 5 \mathrm{~min}\right)$ after each wash, finally resuspended to a 10-fold concentration equivalent in the same buffer containing $10 \mathrm{~mm}-\mathrm{NaF}$, and assayed for retention of GTF and FTF activities.

Antibiotic inhibition studies were done similarly to the sucrose shift assays. A starter culture was added to $\mathrm{CDM} /$ galactose in the proportions given above and grown to the same optical density. At this time, sucrose $(10 \mathrm{mM})$, chloramphenicol $\left(100 \mu \mathrm{g} \mathrm{ml}^{-1}\right)$, rifampicin $\left(100 \mu \mathrm{g} \mathrm{ml}^{-1}\right)$ or combinations of these, were added to samples of the culture which were then incubated at $37^{\circ} \mathrm{C}$ for $1 \mathrm{~h}$. The cells and supernatants were treated as above prior to enzyme assays. The control cultures contained none of these reagents.

Assay of enzyme activities. Dextranase and fructanase activities were determined using a standard assay for reducing sugars designed by Somogyi (1951) and Nelson (1944). Substrate, either dextran Type 100C (Sigma) or levan from Aerobacter levanicum (Sigma), at a final concentration of $0.25 \mathrm{mg} \mathrm{ml}^{-1}$, was incubated with cells or supernatant as prepared above. Reactions were stopped after $180 \mathrm{~min}$. The amount of reducing sugar released (glucose or fructose depending on the substrate) was determined by comparison with glucose or fructose standards. One unit of enzyme activity (U) was defined as the amount of dextranase or fructanase catalysing the release of $1 \mu \mathrm{mol}$ reducing sugar (glucose or fructose) $\mathrm{min}^{-1} \mathrm{ml}^{-1}$. Each data point shows the mean \pm SD of triplicate samples from a representative experiment.

GTF and FTF activities were quantified by a modification of the standard procedure developed by Robrish et al. (1972), where sucrose, labelled either in the glucose or fructose moiety, was incorporated into ethanol-precipitable polymer. Reaction mixtures consisted of: 10 -fold concentrated sample (cells or supernatant), $1 \mathrm{~mm}$-sucrose carrier, $0.25 \mathrm{mg} \mathrm{ml}^{-1}$ dextran or levan primer $\delta$ (Sigma) and labelled sucrose, either $\left[\mathrm{U}^{-14} \mathrm{C}\right] \mathrm{glucose}, 7.7 \times 10^{-5} \mu \mathrm{mol} \mathrm{ml}^{-1}\left(2.8 \mathrm{MBq} \mathrm{ml}^{-1}\right)$, at $261.0 \mathrm{mCi} \mathrm{mmol}^{-1}$, or [U-14 $\mathrm{C}$ ]fructose, $7.5 \times 10^{-5} \mu \mathrm{mol} \mathrm{ml}^{-1}$ (2.8 MBq ml-1), at $267.0 \mathrm{mCi} \mathrm{mmol}^{-1}$ (NEN Research Products). Reactions were carried out in a total volume of $100 \mu 1$ in $12 \times 75 \mathrm{~mm}$ borosilicate disposable culture tubes at $37^{\circ} \mathrm{C}$ for $90 \mathrm{~min}$. The polymer was precipitated with $300 \mu \mathrm{l}$ ice-cold $95 \%$ (v/v) ethanol for at least $30 \mathrm{~min}$. The ethanol-insoluble product was collected on $25 \mathrm{~mm}$ extrathick glass-fibre filters (Gelman Sciences) cut to fit disposable Microfolds (V \& P Scientific). The microfold system is a 96-chamber micro-plate with a small opening in the bottom of each well. The filter rests on top of the opening and immobilizes the precipitate when a vacuum is applied to the bottom of the manifold. Each filter was washed once with ice-cold $95 \%(v / v)$ ethanol and air-dried before being placed in a vial with $3 \mathrm{ml}$ aqueous counting scintillant (ACS) (Amersham). Each sample was counted for $5 \mathrm{~min}$ in a Beckman LS 3801 Liquid Scintillation System. The adaptation of this procedure to a microassay system made it possible to handle multiple samples with greater accuracy and reproducibility. One unit of enzyme activity (U) was defined as the amount of GTF or FTF that catalysed the incorporation of $1 \mathrm{nmol}$ of the glucose or fructose moiety of labelled sucrose $\mathrm{min}^{-1} \mathrm{ml}^{-1}$. Each data point represents the mean $\pm \mathrm{SD}$ of triplicates from a representative experiment. Depending on experimental conditions employed, $65-95 \%$ of the polymer collected from GTF activities, and $90 \%$ of the fructan synthesized in the FTF assays, was water-soluble. No attempt was made to correlate these properties with regulatory effects, as that distinction was beyond the limits of these assays. Therefore, only the total amount of polymer produced was reported.

\section{Results}

Carbon source utilization of $S$. salivarius $P C-1$

In order to develop appropriate culture conditions, $S$. salivarius $\mathrm{PC}-1$ was grown on a number of carbohydrate carbon sources (Fig. 1). When cells were grown on glucose the doubling time at mid-exponential phase was 


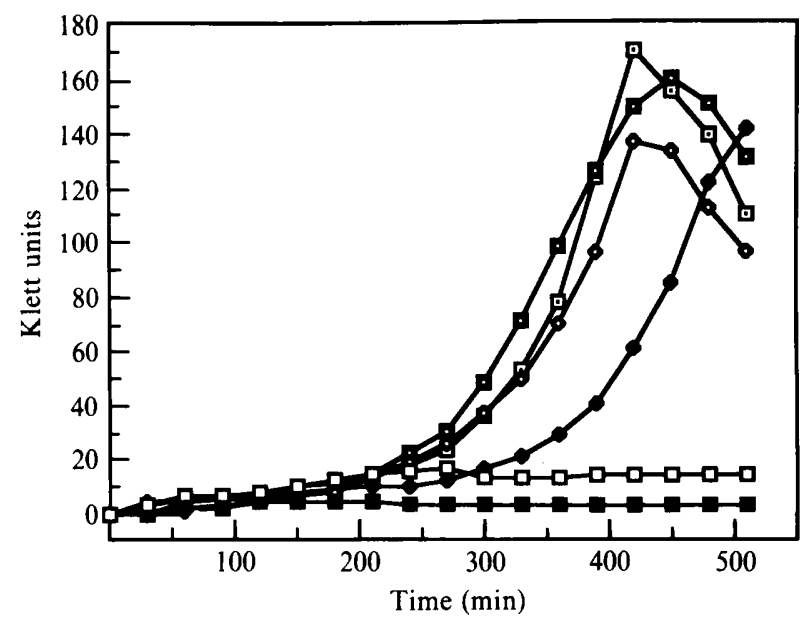

Fig. 1. Carbon source utilization by $S$. salivarius PC-1. Cells were grown in CDM/glucose (10 mM) and aliquots transferred to either: $\square$, $\mathrm{CDM} ; \boldsymbol{\square}, \mathrm{CDM} /$ glucosamine; $\diamond, \mathrm{CDM} /$ galactose; $\mathbf{0}, \mathrm{CDM} /$ sucrose; •, $\mathrm{CDM} /$ fructose; ๑, CDM/glucose. Each sugar concentration was $10 \mathrm{mM}$. Cells were incubated at $37^{\circ} \mathrm{C}$, and $\mathrm{Klett}$ readings were taken as shown.

$49 \mathrm{~min}$. The growth rates at mid-exponential phase were similar for cells grown on either fructose $(60 \mathrm{~min})$, sucrose $(60 \mathrm{~min})$ or galactose $(62 \mathrm{~min})$; however, the lagtime for fructose-grown cells was longer than for the other cultures. Cells did not grow in glucosamine. Cells taken at a Klett reading of 75 were at mid-exponential phase regardless of the carbon source. This allowed the normalization of all subsequent experiments to this value, and the use of galactose as a 'non-sucrose related' carbon source in sucrose-shift assays. Cultures grown in the various sugars, and harvested at an optical density of Klett 75 , had a range of $\mathrm{pH}$ values between $6 \cdot 1$ and 6.4 . Over the duration of the growth experiments, all cultures shifted from an intitial $\mathrm{pH}$ of 7.0 to a final $\mathrm{pH}$ of 4.0 when glucose, galactose, fructose or sucrose was used as the growth substrate.

\section{Dextranase and fructanase activities of $S$. salivarius $P C-1$}

Cultures of PC-1 were grown in $10 \mathrm{mM}$-glucose, fructose, galactose or sucrose, and the dextranase and fructanase activities of cells and culture fluids were measured. Under all conditions tested, cell-associated activity for these enzymes was not detected, indicating that both dextranase and fructanase are extracellular enzymes. If an intracellular dextranase exists in this organism, as in related streptococci (Dewar \& Walker, 1975; Walker et al., 1980; Walker et al., 1981; Russell \& Ferretti, 1990), its activity was not measurable under these conditions. Dextranase levels were similar whether the cells were grown in glucose, fructose or galactose; the same held

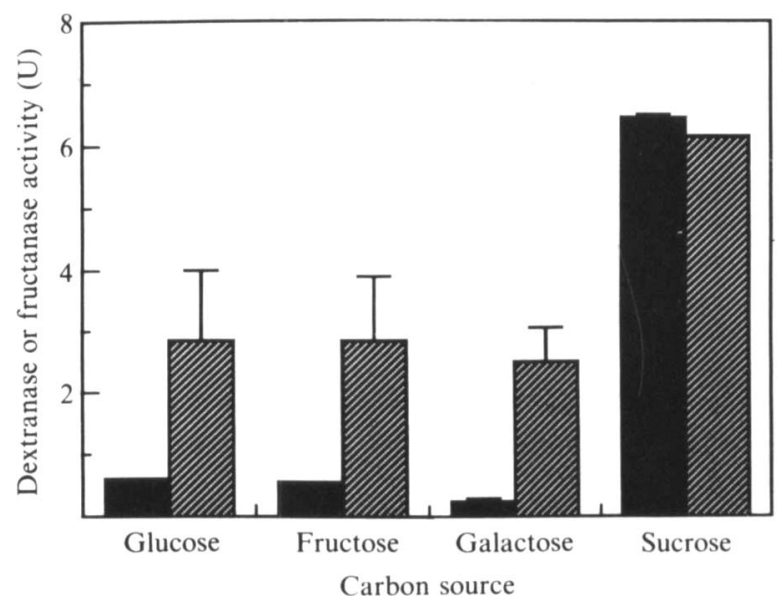

Fig. 2. Effect of carbon source on dextranase and fructanase production by $S$. salivarius $\mathrm{PC}-1$. Cells were grown in $\mathrm{CDM} /$ glucose (10 mM) and transferred to CDM containing either: glucose, fructose, galactose, or sucrose (10 mM each). When cultures reached Klett 75 , supernatants were assayed for dextranase (solid bars) and fructanase (hatched bars) as described in Methods. Each bar represents the mean \pm SD of triplicates from a representative experiment.

true for fructanase (levanase) levels (Fig. 2). Growth in sucrose, however, resulted in 2-fold higher fructanase activity and 10-fold higher dextranase activity. From these preliminary experiments, it appeared that growth in sucrose resulted in significantly increased levels of both dextranase and fructanase activities in culture supernatants.

\section{Effects of sucrose shift on dextranase and fructanase activities}

The response of dextranase and fructanase activities to the addition of sucrose to cells growing on galactose (Fig. 3) was measured. Sucrose addition resulted in a rapid $(<5 \mathrm{~min})$ increase in both dextranase and fructanase activities, followed by a period of stabilization. While fructanase levels increased by $64 \%$ upon the addition of sucrose, dextranase levels increased more than 100 -fold.

\section{Effect of antibiotics on dextranase and fructanase production}

To determine whether the sucrose effect described above was being implemented at the genetic level, previously determined inhibitory concentrations of antibiotics specifically targeted to transcription (rifampicin) or translation (chloramphenicol) were tested. In the absence of sucrose, dextranase levels in culture fluids remained very low whether the cells were untreated, or treated with chloramphenicol or rifampicin (Table 1). However, there was a significant increase (100-fold) in 


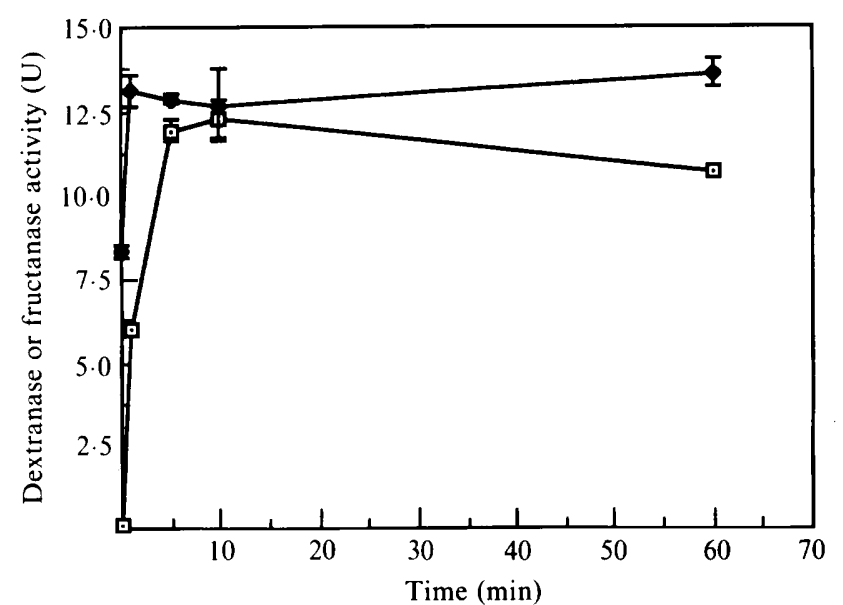

Fig. 3. Effect of sucrose shift on production of dextranase and fructanase in $S$. salivarius $P C-1$. Sucrose $(10 \mathrm{~mm})$ was added to cells grown in CDM/galactose $(10 \mathrm{mM})$ to an optical density of Klett 75 . Aliquots were removed at timed intervals from suspensions held at $37^{\circ} \mathrm{C}$. Supernatants were assayed for dextranase $(\bullet)$ and fructanase $(\bullet)$ activities. Each data point shows the mean \pm SD of triplicates from a representative experiment.

Table 1. Effect of antibiotics on dextranase and fructanase production

An $S$. salivarius $\mathrm{PC}-1 \mathrm{CDM} /$ galactose culture was grown to an optical density of Klett 75 . Sucrose $(10 \mathrm{~mm})$, chloramphenicol $\left(100 \mu \mathrm{g} \mathrm{ml}^{-1}\right)$, rifampicin $\left(100 \mu \mathrm{g} \mathrm{ml}^{-1}\right)$, or combinations of these were added to aliquots of the culture and then incubated at $37^{\circ} \mathrm{C}$ for $1 \mathrm{~h}$. Control cultures contained none of these reagents. The supernatants were treated as described in Methods prior to assaying the extracellular dextranase and fructanase activities. $\mathrm{S}$, sucrose; $\mathrm{C}$, chloramphenicol; $\mathrm{R}$, rifampicin.

\begin{tabular}{lcc}
\hline \hline & \multicolumn{2}{c}{ Enzyme activity $(\mathrm{U})$} \\
\cline { 2 - 3 } Treatment & Dextranase & Fructanase \\
\hline None & $0 \cdot 16 \pm 0.03$ & $6.58 \pm 0$ \\
S & $10 \cdot 67 \pm 0$ & $11 \cdot 72 \pm 0 \cdot 47$ \\
C & $0 \cdot 10 \pm 0.01$ & $6.27 \pm 0 \cdot 12$ \\
S and C & $9 \cdot 89 \pm 0.64$ & $9 \cdot 68 \pm 0.60$ \\
R & $0 \cdot 10 \pm 0.03$ & $6.98 \pm 0.38$ \\
S and R & $10 \cdot 43 \pm 0.25$ & $8 \cdot 76 \pm 0.23$ \\
\hline \hline
\end{tabular}

dextranase activity upon the addition of sucrose, even in the presence of chloramphenicol or rifampicin. It appears, therefore, that the increases in dextranase activity observed in these experiments do not reflect genetic induction, and that regulation at the posttranslational level is likely. Fructanase activity measured under the conditions described was relatively high whether the cells were grown in glucose, fructose or galactose (Fig. 2); therefore, the net increase upon the addition of sucrose was not as dramatic as that seen with dextranase activity (Fig. 3). Furthermore, unlike dextranase, this increase was reduced significantly, from $78 \%$ with sucrose alone to $47 \%$ and $33 \%$, respectively, by

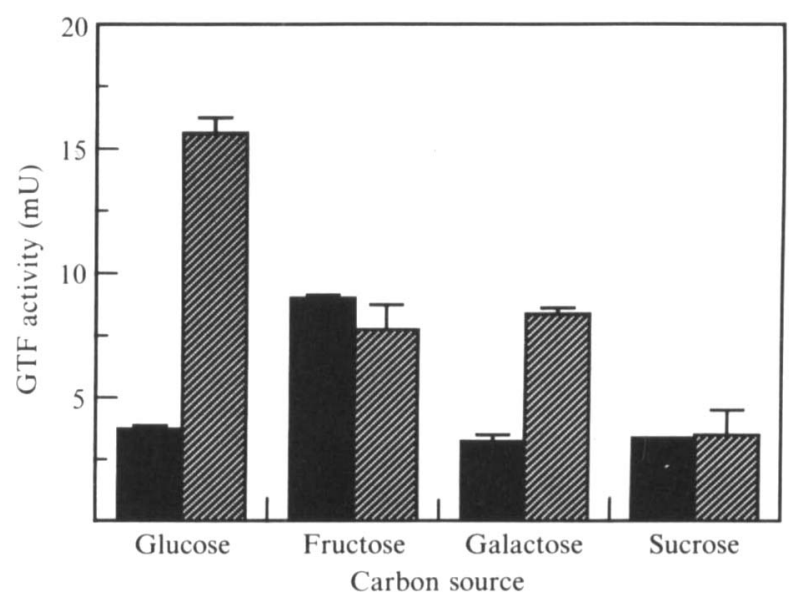

Fig. 4. Effect of carbon source on cell-associated and extracellular GTF production in $S$. salivarius $P C-1$. Cells were grown in CDM/glucose $(10 \mathrm{mM})$ and transferred to CDM containing either: glucose, fructose, galactose, or sucrose (10 mM each). Cultures were harvested at Klett 75 after growth at $37^{\circ} \mathrm{C}$ and cell-associated (solid bars) and extracellular (hatched bars) GTF activities were assayed as described in Methods. Each bar represents the mean \pm SD of triplicates from a representative experiment.

transcriptional and translational inhibitors (Table 1), indicating a possible genetic induction.

\section{GTF and FTF activities of $S$. salivarius $P C-1$}

These experiments were performed with and without a dextran or levan primer for GTF or FTF, respectively. The addition of primer increased the number of precipitable counts in the GTF assays by approximately $15-25 \%$, and the precipitable counts in the FTF assay by $10-15 \%$. Data presented here are from experiments that include primer.

The measurable activities of both cell-associated and released GTF were quite low. This was probably due to the presence of dextranase, which was able to solubilize the radiolabelled products. This theory was supported by the apparent inverse relationship between the amounts of GTF activity (Fig. 4) and dextranase activity (Fig. 2) measured under these conditions. Cell-associated GTF activity was similar in cells grown on sucrose, galactose, or glucose, and higher in cells grown on fructose (Fig. 4). Glucose-grown cells produced the highest apparent activity of the secreted form of GTF as compared to fructose-, sucrose-, or galactose-grown cells.

Cell-associated FTF activity was greater than extracellular activity when cells were grown in glucose, fructose, or galactose (Fig. 5). However, soluble FTF activity increased when cells were grown on sucrose. The total FTF activity for sucrose-grown cultures was about 2-fold greater than that for galactose-grown cultures (Fig. 5). 


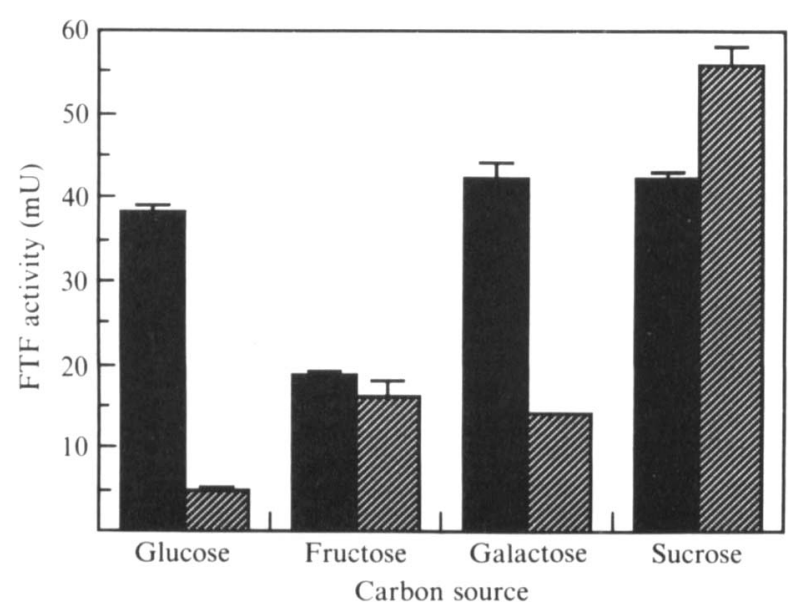

Fig. 5. Effect of carbon source on cell-associated and extracellular FTF production in $S$. salivarius PC-1. Cells were grown in CDM/glucose (10 mM) and transferred to CDM containing either: glucose, fructose, galactose, or sucrose (10 mM each). Cultures were harvested at Klett 75 after growth at $37^{\circ} \mathrm{C}$ and cell-associated (solid bars) and extracellular (hatched bars) FTF activities were assayed as described in Methods. Each bar represents the mean \pm SD of triplicates from a representative experiment.

\section{Effect of sucrose shift on GTF and FTF activities}

When sucrose was added to cells growing in galactose, cell-associated GTF activity appeared to increase initially, but remained low (Fig. 6a). In contrast, released activity showed an initial decline before returning to original values, suggesting a sucrose-mediated, cellassociation of secreted GTF. As seen in Fig. 5, the majority of FTF activity was cell-associated when the cells were grown in galactose. However, $5 \mathrm{~min}$ after the addition of sucrose, there was a complete reversal of the location of FTF activity (Fig. 6b). This translocation effect was immediate and profound.

To investigate the nature of the cell-surface interactions of these enzymes, galactose-grown cells were subjected to a number of different washing procedures and then assayed for GTF and FTF activities. The $0.04 \%$ SDS wash removed $95 \%$ of cell-associated GTF activity, but reduced cell-associated FTF by only $34 \%$. No FTF activity was dissociated from the cell surface by Tween 80 at any concentration, whereas cell-associated GTF activity was reduced $57 \%$ by $0.06 \%$ Tween $80,71 \%$ by $0.04 \%$ Tween and $81 \%$ by $0.02 \%$ Tween.

It became important to determine if there was genetic induction following the addition of sucrose that might account for the ultimate increase in total GTF and FTF activities over time.

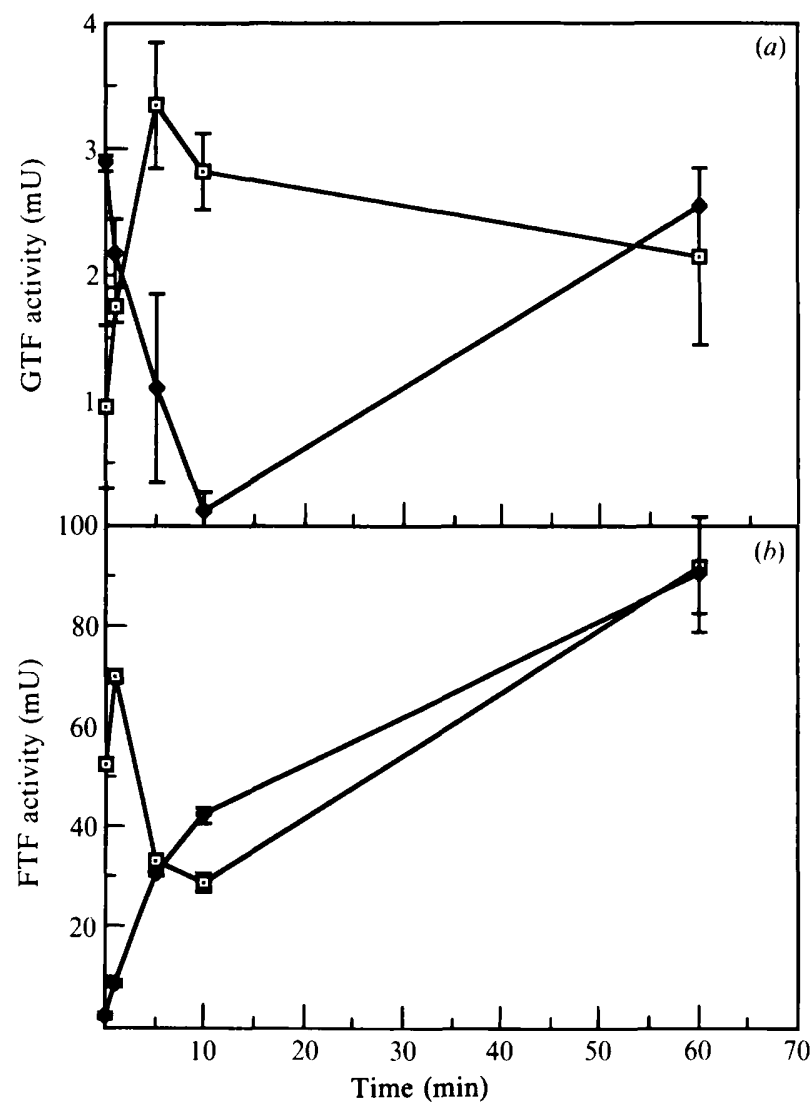

Fig. 6. Effect of sucrose shift on production and distribution of GTF and FTF in $S$. salivarius PC-1. Sucrose $(10 \mathrm{~mm})$ was added to $S$. salivarius $\mathrm{PC}-1$ grown in CDM/galactose $(10 \mathrm{mM})$ at $37^{\circ} \mathrm{C}$ to an optical density of Klett 75 . Aliquots were removed at timed intervals as shown and cell-associated $(\bullet)$ and extracellular $(\bullet)$ glycosyltransferase activities were determined as described in Methods. (a) GTF activity; (b) FTF activity. Each data point shows the mean \pm SD of triplicates from a representative experiment.

\section{Effect of antibiotics on GTF and FTF production}

An inhibition experiment similar to that described for dextranase and fructanase (Table 1) was performed for the glycosyltransferases. The untreated control and rifampicin- or chloramphenicol-treated cells exhibited less cell-associated GTF activity than the extracellular GTF activity (Table 2). The total GTF activity in response to each of these treatments was very similar, although rifampicin treatment caused an unexpected release of GTF activity into the fluid phase. Upon the addition of sucrose, extracellular activity remained constant, while cell-associated activity increased almost 4-fold. The total GTF activity was 2-fold higher in the presence than in the absence of sucrose. Transcriptional and translational inhibitors, in conjunction with sucrose, however, decreased the amount of extracellular GTF activity by $69-71 \%$ when compared with untreated control and sucrose-exposed cultures. 
Table 2. Effect of antibiotics on glucosyltransferase production

An $S$. salivarius $\mathrm{PC}-1 \mathrm{CDM} /$ galactose culture was grown to an optical density of Klett 75 . Sucrose $(10 \mathrm{~mm})$, chloramphenicol $\left(100 \mu \mathrm{g} \mathrm{ml}^{-1}\right)$, rifampicin $\left(100 \mu \mathrm{g} \mathrm{ml}^{-1}\right)$, or combinations of these were added to aliquots of the culture and then incubated at $37^{\circ} \mathrm{C}$ for $1 \mathrm{~h}$. Control cultures contained none of these reagents. The cells and supernatants were treated as described in Methods prior to assaying the GTF activities. Symbols as in Table 1 .

\begin{tabular}{lccc}
\hline & \multicolumn{3}{c}{ GTF activity (mU) } \\
\cline { 2 - 4 } Treatment & Cell-associated & Extracellular & Total \\
\hline None & $0.74 \pm 0.13$ & $2.95 \pm 0.84$ & 3.69 \\
S & $3.52 \pm 0.10$ & $3.43 \pm 0.12$ & 6.95 \\
C & $0.34 \pm 0.09$ & $2.86 \pm 0.06$ & 3.20 \\
S\&C & $3.21 \pm 0.04$ & $1.08 \pm 0.24$ & 4.29 \\
R & $0.43 \pm 0.03$ & $5.44 \pm 0.23$ & 5.87 \\
S\&R & $3.31 \pm 0.07$ & $1.00 \pm 0.02$ & 4.31 \\
\hline \hline
\end{tabular}

Table 3. Effect of antibiotics on fructosyltransferase production

An $S$. salivarius $\mathrm{PC}-1 \mathrm{CDM} /$ galactose culture was grown to an optical density of Klett 75 . Sucrose (10 mM), chloramphenicol $\left(100 \mu \mathrm{g} \mathrm{ml}^{-1}\right)$, rifampicin $\left(100 \mu \mathrm{g} \mathrm{ml}^{-1}\right)$, or combinations of these were added to aliquots of the culture and then incubated at $37^{\circ} \mathrm{C}$ for $1 \mathrm{~h}$. Control cultures contained none of these reagents. The supernatants were treated as described in Methods prior to assaying the FTF activities. Symbols as in Table 1.

\begin{tabular}{lcrr}
\hline \hline & & \multicolumn{3}{c}{ FTF activity (mU) } \\
\cline { 2 - 4 } Treatment & Cell-associated & Extracellular & Total \\
\hline None & $31.44 \pm 0.46$ & $5.06 \pm 0.01$ & 36.50 \\
S & $40.31 \pm 1.76$ & $34.38 \pm 0.25$ & 74.69 \\
C & $35.76 \pm 1.94$ & $5.01 \pm 0.01$ & 40.77 \\
S\&C & $11.52 \pm 0.03$ & $30.77 \pm 0.15$ & 42.29 \\
R & $47.28 \pm 0.26$ & $4.03 \pm 0.09$ & 51.31 \\
S\&R & $10.89 \pm 0.01$ & $26.67 \pm 1.91$ & 37.56 \\
\hline \hline
\end{tabular}

The cell-associated form of FTF predominated in galactose-grown, and in rifampicin- and chloramphenicol-treated cells; however, upon the addition of sucrose, extracellular FTF activity increased almost 7 -fold while cell-associated activity remained unchanged (Table 3 ). When chloramphenicol or rifampicin was added together with sucrose, extracellular FTF levels remained constant, but cell-associated FTF activity decreased sharply (71-73\%). Total FTF activity was highest when sucrose was added without chloramphenicol or rifampicin. Taken in aggregate, these data indicate both genetic and non-genetic regulation of FTF by its substrate sucrose.

\section{Discussion}

In studies such as those presented above, differential enzyme production due to growth phase variations or enzyme degradation in ageing cultures must be avoided. Growth experiments were therefore run extensively, to determine the optimum stage at which cells grew at a consistent rate without exhausting nutrients. This made it possible to normalize all experiments by growing the cells to a predetermined point in mid-exponential phase regardless of further treatment. The use of single sugars as sole carbon sources in a chemically defined medium minimized the effects of nutrition which could complicate interpretation of results. Fortunately, $S$. salivarius PC-1 utilized galactose at a rate similar to that of sucrose and other sugars. This allowed the use of galactose as a 'non-sucrose related' carbon-source for the sucrose-shift experiments. The $\mathrm{pH}$ levels $(6 \cdot 1-6 \cdot 4)$ of $S$. salivarius $\mathrm{PC}-1$ cultures grown to an optical density of Klett 75 , regardless of the sugar used, were well within the ranges determined by others for optimal GTF (McCabe \& Smith, 1973), dextranase (Walker et al., 1980), FTF (Wenham et al., 1979), and fructanase (Jacques et al., $1985 b$ ) production.

Cell preparation and treatment were also designed to be consistent within all experiments. This uniform approach provided cells at equivalent mass, growth phase and concentration, and allowed comparison of cell-associated and extracellular enzyme activities under different experimental conditions. The activities measured were taken to be an indication of the relative amounts of enzyme produced. The products assayed in the GTF and FTF experiments were the net result of synthesis (by GTF and FTF) and also degradation (by dextranase and fructanase). On the other hand, the substrate for GTF and FTF (sucrose) was not present in the dextranase and fructanase assays and therefore could not have contributed to the net amount of product.

Chassy et al. (1976) found that the presence of sucrose reduced GTF activity in culture fluids of $S$. salivarius, but did not see a shift to the cell-associated form. These investigators were unable to distinguish between repression of GTF by sucrose and modification of the activity of constitutive GTF levels. In the present study, when sucrose was added to growing cells, GTF activity became associated with the cell surface (Fig. 6a). The nature of this surface interaction is different from that observed with FTF, since GTF activity, but not FTF activity, can be washed from the surface with SDS and low concentrations of Tween 80 .

Recently, Aduse-Opoku et al. (1989), have shown that the glucan-binding protein of $S$. mutans becomes bound to the cell surface on exposure to sucrose. If dextran were to form a bridge between the glucan-binding domain of 
GTFs (Mooser \& Wong, 1988) and these surface-bound glucan-binding lectins (Drake et al., 1988; Banas et al., 1990), washing with detergents may solubilize the dextran, releasing the GTF activity. McCabe \& Smith (1973) reached similar conclusions concerning the binding of the GTFs of $S$. mutans. Another theory (Umesaki et al., 1977; Wittenberger et al., 1978; Jacques et al., 1985a) is that GTF synthesis and release is regulated by changes in the membrane fluidity determined by its fatty acid composition.

The $g t f B$ and $g t f C$ genes from $S$. mutans have been cloned (Aoki et al., 1986; Pucci et al., 1987; Hanada \& Kuramitsu, 1988) and sequenced (Shiroza et al., 1987; Ueda et al., 1988). The nucleotide sequences designated the gene products as extracellular enzymes in that putative signal sequences were present and membrane anchor sequences were absent. This further supports the conclusion that cell-association of GTF activity is mediated by factors other than wall- or membraneanchoring domains in the GTF molecule, and that cellassociated and extracellular activities may be mediated by the same enzyme species.

Inhibitor studies (Table 2) and studies by other investigators (Janda \& Kuramitsu, 1976; Montville et al., 1977; Janda \& Kuramitsu, 1978) indicate that de novo protein synthesis may be required for the synthesis of at least one extracellular GTF. Recently, Hudson \& Curtiss (1990) showed an increase in the expression of $\mathrm{gtfB} / \mathrm{C}$ from $S$. mutans in the presence of sucrose, thereby providing additional evidence of genetic regulation of this enzyme by its substrate in the oral streptococci. This production, followed by association of GTF activity to whole cells, may be part of a dynamic process involving glucan-binding lectins or still-unknown surface proteins. The changes in GTF activity seen upon addition of sucrose are difficult to define biochemically, because this molecule may have multiple effects on the regulation (genetic induction), location (cell-association) and measurable activity (antagonistic effects of dextranase) of this enzyme. Furthermore, each of these phenomena may differ for the individual GTFs in $S$. salivarius as recently described by Pitty et al. (1989). However, data presented here and by others (Janda \& Kuramitsu, 1976; Montville et al., 1977; Janda \& Kuramitsu, 1978; Hudson \& Curtiss, 1990) suggest that sucrose regulates the synthesis and distribution of GTF and that these two phenomena are independent of each other.

The gene encoding the $S$. mutans GS-5 FTF has been cloned (Sato \& Kuramitsu, 1986) and sequenced (Shiroza \& Kuramitsu, 1988). All indications have been that this enzyme, like GTF, is a secreted protein. Yet Fig. $6 b$ and Table 3 clearly show that, in the absence of sucrose, the majority of FTF activity is found on the cell surface of $S$. salivarius, as previously demonstrated by Chassy et al.
(1976). Several hypotheses regarding the location and activity of FTF have been formulated. It has been postulated that the cell-associated form of FTF is inactivated by proteolytic degradation (Jacques \& Wittenberger, 1981), that FTF may be associated with the cytoplasmic membrane (Jacques, 1985), and that the lipid content of the membrane is responsible for the regulation and release of this enzyme (Pitty \& Jacques, 1987). However, we suggest that the rapid release of this activity from the cell surface upon addition of sucrose as seen in Fig. $6 b$ and Table 3, and recently confirmed by Milward \& Jacques (1990), is due to FTF having a greater affinity for sucrose than for the surface framework to which it may be bound. This establishes a biological basis for the translocation phenomenon and also suggests that the distribution of FTF is regulated independently of its synthesis. The inability of either ionic or non-ionic detergents to wash cell-associated FTF activity from the cell surface would suggest that the enzyme is specifically bound, rather than held through nonspecific hydrophilic or hydrophobic interactions.

While a significant amount of the FTF activity can be recovered in the supernatant after addition of sucrose, this does not fully account for the 2-fold increase in total activity (Table 3). Hudson \& Curtiss (1990) have shown that in $S$. mutans, such an effect may be due to increased transcriptional levels. Nucleotide sequence analysis has revealed regions of the $S$. mutans FTF gene which may be involved in its genetic regulation (Shiroza \& Kuramitsu, 1988). S. salivarius may also regulate FTF production by substrate induction, but the sucrose-mediated release of FTF shown above clearly requires a surface-localized binding site for FTF. It is presently unclear whether this specialized binding protein must be synthesized and transported to the cell surface along with the FTF. However, the data in Table 3 indicate that de novo protein synthesis is in some way associated with the induction of cell-bound FTF by sucrose.

In this study, we show that $S$. salivarius dextranase activity resides in the supernatant, rather than the cell, and that this activity increases at least 100 -fold in the presence of sucrose. We also show that this is most likely not a genetic induction, since neither chloramphenicol nor rifampicin affects dextranase production in the presence of sucrose. This should be compared with the effects of these inhibitors on fructanase (Table 1) where there is significant inhibition indicating possible genetic induction. Sucrose may activate an otherwise inactive form of dextranase through some type of conformational change. However, since recombinant dextranase is active in the absence of sucrose (unpublished results) we believe that sucrose may act to release dextranase from a putative dextranase-inhibitor. Hamelik \& McCabe (1982) have shown that in Streptococcus sobrinus the 
majority of dextranase is in a tightly bound, inactive, enzyme-inhibitor complex. An effector (presumably sucrose) with a high affinity for the inhibitor would be required for activation of dextranase.

Dextranase could act on the dextran polymer to provide primer or branch points for GTF (Walker, 1972; Germaine et al., 1977). If involvement in glucan formation is a major function of dextranase, the ratio of $\alpha-(1 \rightarrow 3)$ to $\alpha-(1 \rightarrow 6)$ glycosidic linkages and therefore the solubility properties of dextran made by $S$. salivarius and other organisms may be altered. This would have a potential impact on colonization, plaque formation and caries development. Activation of dextranase by sucrose in order to modify dextran synthesis, therefore, is readily understandable.

Alternatively, dextranase could act at the beginning of a catabolic pathway, resulting in the breakdown of dextran to eventually yield glucose (Hamada et al., 1975; Schachtele et al., 1975). It is known that extracellular dextranase acts as an endoenzyme, cleaving the dextran into smaller polymers, predominantly isomaltosaccharides (Dewar \& Walker, 1975). A regulatory role for sucrose in the catabolic function of dextranase is less obvious. However, from an energetic standpoint, the synthesis and degradation of glucans relies solely on bond energy. The short isomaltosaccharides released by the extracellular endodextranase should be readily transported across the cell membrane where an intracellular exodextranase, such as those recently cloned from $S$. mutans by Burne et al., 1986 and Russell \& Ferretti, 1990 , would further degrade these short polymers to glucose. If this energy-efficient system for obtaining glucose exists in $S$. salivarius, the extracellular endodextranase could play a key catabolic role in the physiology of this species and regulation by sucrose would be understandable.

Furthermore, in this catabolic capacity, dextranase would be acting as an antagonist to the extracellular GTFs, thus explaining the apparent low levels of GTF activity in this organism. In fact, the presence of dextranase may obscure any conclusions made in studies of GTF in any organism producing both these enzyme activities and consequently, any reaction influenced by dextran (aggregation, adherence and the distribution of GTFs between cell-surfaces and culture supernatants) (Walker et al., 1981). Work is continuing on determining the molecular basis of sucrose activation of dextranase, and the effect of dextranase on the apparent production of GTF. Recently, we cloned the extracellular endodextranase of $S$. salivarius (unpublished results). This should allow the construction of an isogenic, dex- mutant, unable to produce dextranase yet capable of producing GTFs, permitting a more comprehensive study of these biological mechanisms.
Work reported in this paper was supported by a Ford Foundation Fellowship to P.T. L. and a Public Health Service grant no. DE-08007 to A.S. B. This work was presented in part at the $89^{\text {th }}$ Annual Meeting of the American Society for Microbiology, New Orleans, La., 14-18 May 1989 (Townsend \& Bleiweis, 1989).

\section{References}

Aduse-Opoku, J., Gilpin, M. \& Russell, R. (1989). Genetic and antigenic comparison of Streptococcus mutans fructosyltransferase and glucan-binding protein. FEMS Microbiology Letters 59, 279282.

aoki, H., Shiroza, T., Hayakawa, M., Sato, S. \& Kuramitsu, H. (1986). Cloning of a Streptococcus mutans glucosyltransferase gene coding for insoluble glucan synthesis. Infection and Immunity 53, 587594.

Banas, J., Russell, R. \& Ferretti, J. (1990). Sequence analysis of the gene for the glucan-binding protein of Streptococcus mutans Ingbritt. Infection and Immunity 58, 667-673.

Burne, R., Rubinfeld, B., Bowen, W. \& Yasbin, R. (1986). Tight genetic linkage of a glucosyltransferase and dextranase of Streptococcus mutans GS-5. Journal of Dental Research 65, 1392-1401.

Carlsson, J. \& Johansson, T. (1973). Sugars and the production of bacteria in the human mouth. Caries Research 7, 273-282.

Chassy, B., Beal, J., Bielawski, R., Porter, E. \& Donkersloot, J. (1976). Occurrence and distribution of sucrose-metabolizing enzymes in oral streptococci. Infection and Immunity 14, 408-415.

CURTISS, R., III, GOLDSCHMIDT, R., BARRETT, J., THOREN-GoRDON, M., Salzberg, D., Murchison, H. \& MichaleK, S. (1987). Genetic analysis of surface proteins essential for virulence of Streptococcus sobrinus. In Streptococcal Genetics, pp. 212-216. Edited by J. Ferretti \& R. Curtiss. Washington, DC: American Society for Microbiology.

DEWAR, M. \& WaLKER, G. (1975). Metabolism of the polysaccharides of human dental plaque. Caries Research 9, 21-35.

Drake, D., Taylor, K., Bleiweis, A. \& Doyle, R. (1988). Specificity of the glucan-binding lectin of Streptococcus cricetus. Infection and Immunity 56, 1864-1872.

Germaine, G., Harlander, S., Leung, W. \& Schachtele, C. (1977). Streptococcus mutans dextransucrase: Functioning of primer dextran and endogenous dextranase in water-soluble and water-insoluble glucan synthesis. Infection and Immunity 16, 637-648.

GibBons, R. \& VAN Houte, J. (1973). On the formation of dental plaques. Journal of Periodontology 44, 347-360.

GibBons, R. \& VAN HouTE, J. (1975). Bacterial adherence in oral microbial ecology. Annual Review of Microbiology 29, 19-44.

HAMADA, S. \& SLADE, H. (1980). Biology, immunology, and cariogenicity of Streptococcus mutans. Microbiological Reviews 44, 331-384.

Hamada, S., Mizuno, J., Murayama, Y., Ooshima, R., Masuda, N. \& SOBUE, S. (1975). Effect of dextranase on the extracellular polysaccharide synthesis of Streptococcus mutans: chemical and scanning electron microscopy studies. Infection and Immunity 12, $1415-1425$.

HAMELIK, R. \& MCCABE, M. (1982). An endodextranase EC 3.2.1.11 inhibitor from batch cultures of $S$. mutans. Biochemical and Biophysical Research Communications 106, 875-880.

HANADA, N. \& KURAmitsu, H. (1988). Isolation and characterization of the Streptococcus mutans gifC gene, coding for synthesis of both soluble and insoluble glucans. Infection and Immunity 56, 19992005 .

Houck, C., Pear, J., Elliott, R. \& Perchorowicz, J. (1987). Isolation of DNA encoding sucrase genes from Streptococcus salivarius and partial characterization of the enzymes expressed in Escherichia coli. Journal of Bacteriology 169, 3679-3684.

Hudson, M. \& CurTiss III, R. (1990). Regulation of expression of Streptococcus mutans genes important to virulence. Infection and Immunity 58, 464-470.

JACQUES, N. (1985). Inhibition of the expression of cell-associated fructosyltransferase in Streptococcus salivarius by octyl $\beta$-D-glucopyranoside. Journal of General Microbiology 131, 3243-3250. 
JACQUES, N. \& WITTENBERGER, C. (1981). Inactivation of cellassociated fructosyltransferase in Streptococcus salivarius. Journal of Bacteriology 148, 912-918.

JaCQUES, N., JACQUES, V., Wolf, A. \& WitTENBerger, C. (1985a). Does an increase in membrane unsaturated fatty acids account for Tween 80 stimulation of glucosyltransferase secretion by Streptococcus salivarius? Journal of General Microbiology 131, 67-72.

JACQUES, N., MORREY-JONES, J. \& WALKER, G. (1985b). Inducible and constitutive formation of fructanase in batch and continuous cultures of Streptococcus mutans. Journal of General Microbiology 131, 16251633.

JANDA, W. \& KURAMITSU, H. (1976). Regulation of extracellular glucosyltransferase production and the relationship between extracellular and cell-associated activities in Streptococcus mutans. Infection and Immunity 14, 191-202.

JaNDA, W. \& KuRamitsu, H. (1978). Production of extracellular and cell-associated glucosyltransferase activity by Streptococcus mutans during growth on various carbon sources. Infection and Immunity 19, $116-122$.

Keevil, C., West, A., Marsh, P. \& Ellwood, D. (1983). Batch versus continuous culture studies of glucosyltransferase synthesis in oral streptococci. In Glucosyltransferases, Glucans, Sucrose and Dental Caries, pp. 189-200. Edited by R. Doyle \& J. Ciardi. Oxford: IRL Press.

Koga, T., Asakawa, H., Okahashi, N. \& Hamada, S. (1986). Sucrosedependent cell adherence and cariogenicity of serotype c Streptococcus mutans. Journal of General Microbiology 132, 2873-2883.

MCCABE, M. \& SMITH, E. (1973). Origin of the cell-associated dextransucrase of Streptococcus mutans. Infection and Immunity 7 , 829-838.

McCABE, M. \& SMith, E. (1975). Relationship between cell-bound dextransucrase and the agglutination of Streptococcus mutans. Infection and Immunity 12, 512-520.

MILWARD, C. \& JACQUES, N. (1990). Secretion of fructosyltransferase by Streptococcus salivarius involves the sucrose-dependent release of the cell-bound form. Journal of General Microbiology 136, 165-169.

Montville, T., CoONey, C. \& Sinskey, A. (1977). Distribution of Streptococcus mutans and observations on the effect of soluble dextran on dextransucrase activities. Infection and Immunity 18, 629635

MoOSER, G. \& WoNG, C. (1988). Isolation of a glucan-binding domain of glucosyltransferase (1,6- $\alpha$-glucan synthase) from Streptococcus sobrinus. Infection and Immunity 56, 880-884.

Nelson, N. (1944). A photometric adaptation of the Somogyi method for the determination of glucose. Journal of Biological Chemistry 153, 375-380.

PitTy (née Markevics), L. \& JacQues, N. (1987). The influence of incorporation of octadecenoic acid on the cell-associated fructosyltransferase and the extracellular glucosyltransferase activities on Streptococcus salivarius. Journal of General Microbiology 133, 35653573.

PitTy, L., Giffard, P., Gilpin, M., Russell, R. \& JacQues, N. (1989). Cloning and expression of glycosyltransferase activities from Streptococcus salivarius. Journal of Dental Research 68, 1681-1682.

Pucci, M., Jones, K., Kuramitsu, H. \& Macrina, F. (1987). Molecular cloning and characterization of the glucosyltransferase $C$ gene $(\mathrm{gtf} C)$ from Streptococcus mutans LM7. Infection and Immunity 5 , 2176-2182.

Robrish, S., REID, W. \& KRICHEVSKY, M. (1972). Distribution of enzymes forming polysaccharide from sucrose and the composition of extracellular polysaccharide synthesized by Streptococcus mutans. Applied Microbiology 24, 184-190.

RUSSELL, R. \& FERRETTI, J. (1990). Nucleotide sequence of the dextran glucosidase (dexB) gene of Streptococcus mutans. Journal of General Microbiology 136, 803-810.

SATO, S. \& KURAMITSU, H. (1986). Isolation and characterization of a fructosyltransferase gene from Streptococcus mutans GS-5. Infection and Immunity 52, 166-170.
Sato, S., Ueda, S. \& Kuramitsu, H. (1987). Construction of Streptococcus mutans glucosyltransferase mutants utilizing a cloned gene fragment. FEMS Microbiology Letters 48, 207-210.

SCHaChtele, C., StaAt, R. \& Harlander, S. (1975). Dextranases from oral bacteria: inhibition of water-insoluble glucan production and adherence to smooth surfaces by Streptococcus mutans. Infection and Immunity 12, 309-317.

SCHROEDER, V., MichaleK, S. \& MaCrina, F. (1989). Biochemical characterization and evaluation of virulence of a fructosyltransferase-deficient mutant of Streptococcus mutans V403. Infection and Immunity 57, 3560-3569.

SHIROZA, R. \& KURAMITSU, H. (1988). Sequence analysis of the Streptococcus mutans fructosyltransferase gene and flanking regions. Journal of Bacteriology 170, 810-816.

Shiroza, R., UEDA, S. \& KURAMITSU, H. (1987). Sequence analysis of the gtfB gene from Streptococcus mutans. Journal of Bacteriology 169 , $4263-4270$.

SoMOGYI, M. (1951). Notes on sugar determination. Journal of Biological Chemistry 170, 19-23.

De Stopelaar, J., van Houte, J. \& Backer Dirks, O. (1970). The effect of carbohydrate restriction on the presence of Streptococcus mutans, Streptococcus sanguis and iodophilic polysaccharide-producing bacteria in human dental plaque. Caries Research 4, 114-123.

TaKaHASHI, N., Mizumo, F. \& Takamori, K. (1983). Isolation and properties of levanase from Streptococcus salivarius KTA-19. Infection and Immunity 42, 231-236.

Terleckyj, B., Willett, N. \& Shockman, G. (1975). Growth of several cariogenic strains of oral streptococci in a chemically defined medium. Infection and Immunity 11, 649-655.

TOWNSEND, P. \& Bleiweis, A. S. (1989). Regulation of sucrose metabolism in Streptococcus salivarius. Annual Meeting of the American Society for Microbiology 1989, p. 266. Washington DC: ASM.

Ueda, S., Shiroza, T. \& Kuramitsu, H. (1988). Sequence analysis of the gtfC gene from Streptococcus mutans GS-5. Gene 69, 101-109.

Umesaki, Y., KawaI, Y. \& MUTAI, M. (1977). Effect of Tween 80 on glucosyltransferase production in Streptococcus mutans. Applied and Environmental Microbiology 34, 115-119.

WALKER, G. (1972). Some properties of a dextranglucosidase isolated from oral streptococci and its use in studies on dextran synthesis. Journal of Dental Research 51, 409-414.

WaLKeR, G. \& JACQues, N. (1987). Polysaccharides of oral streptococci. In Sugar Transport and Metabolism in Gram-Positive Bacteria, pp. 39-68. Edited by J. Reizer and A. Peterkofsky. Chichester: Ellis Horwood Ltd.

WALKER, G., MURRAY, V. \& MORREY-JoNES, J. (1980). Regulation of dextranase synthesis by Streptococcus mutans. FEBS Letters 115, 206-208.

WALKer, G., PUlkownIK, A. \& Morrey-Jones, J. (1981). Metabolism of the polysaccharides of human dental plaque: release of dextranase in batch cultures of Streptococcus mutans. Journal of General Microbiology 127, 201-208.

Walker, G., Morrey-Jones, J., Svensson, S. \& Taylor, C. (1983). Effect of variation in growth conditions on the activity of Dglucosyltransferases and the synthesis of $\alpha$-D-glucans by Streptococcus mutans OMZ176. In Glucosyltransferases, Glucans, Sucrose and Dental Caries, pp. 179-187. Edited by R. Doyle \& J. Ciardi. Oxford: IRL Press.

WeErKamp, A. \& McBride, B. (1980). Adherence of Streptococcus salivarius HB and HB-7 to oral surfaces and saliva-coated hydroxyapatite. Infection and Immunity 30, 150-158.

Wenham, D., HenNessey, T. \& Cole, J. (1979). Regulation of glucosyland fructosyltransferase synthesis by continuous cultures of Streptococcus mutans. Journal of General Microbiology 114, 117-124.

WenhaM, D., Davies, R. \& CoLE, J. (1981). Insoluble glucan synthesis by mutansucrase as a determinant of the cariogenicity of Streptococcus mutans. Journal of General Microbiology 127, 407-415.

Wittenberger, C., Beaman, A. \& Lee, L. (1978). Tween 80 effect on glucosyltransferase synthesis by Streptococcus salivarius. Journal of Bacteriology 133, 231-239. 